\title{
EXTREMIST PROPAGANDA AND THE "POLITICS OF THE INTERNET"1.
}

Julian Richards, University of Buckingham

\section{Introduction}

Ten years on from the commencement of a series of events that became known as the Arab Spring: a period in which populist movements and contested elections have increasingly characterised the political landscape; we have an opportunity to reflect on what the "politics of the internet" may mean for populist and extremist movements and their propaganda. At one level, we could argue that the internet surely cannot have any politics of its own, much as oxygen, water, or even guns are just things or phenomena without human agency. On another level, however, perhaps the internet is crucially different from phenomena such as the natural environment, as it is created, operated, and governed by humans with political interests.

In this paper, I review some of the discussions about the politics of the internet and relate them to our most recent understanding of rapidly evolving Violent Transnational Social Movements (VTSMs). I frame the analysis in terms of the key actors involved in shaping and governing the internet, organised as a triumvirate of citizen, state and internet service provider (ISP). I conclude that the internet may not be as powerful a force in shaping democracy as we may think, although further research and experience of a rapidly evolving situation will be critical. I also suggest that the state has more power to shape the situation to its interests than we might suppose, and this has a major bearing on the formulation of counter-extremism policy and strategy.

\section{Questions of power and space}

Inevitably, we tend to think of rapidly growing and evolving situations in tried-and-tested historical terms since those are the only conceptual models we have readily available. The internet and social media also deliver a sort of parallel universe of conceptual difficulty: a virtual world that mirrors the physical, but with crucial differences. Much as people communicate with each other and develop their political messages in the physical world, so increasingly - do they communicate and interact in new and complex ways on internet-based platforms. It seems inevitable that this should effect a change to communication and to politics, but how, and how much?

In the context of extremism, popular and violent social movements have a long history dating far back before the advent of the internet, of course. Rebel and insurgent movements and popular revolutions before the end of the

\footnotetext{
${ }^{1}$ Paper delivered at the 2020 CASIS West Coast Security Conference.
} 
twentieth century relied on physical interactions, or fairly rudimentary communications such as the printing press or radio. Even today, the symbolic significance of the "physical space" to particular movements, ideologies and events can still be large, colouring our reporting of situations and forming a focal point for those joining the movement. We can think of Cairo's Tahrir Square in the early period of the Arab Spring, for example, in which gathering masses could be beamed around the world and give the impression that something bigger was happening than the state could stop. Similarly, the location of Zucotti Park in New York is usually mentioned in the same breath as the Occupy Wall Street movement, acting as it did as a focal point for protestors to assemble and cause a problem for those attempting their dispersal. These spaces have not disappeared, and they still play an iconic role in the rise of popular movements. In the contemporary environment, however, we see many of the same things that would happen in such places taking place on the internet, such as the development of cultural memes and trends, the sharing of stories, and the recruitment of new supporters. So, is the internet the new "political space" for populist movements?

The answer to some of these questions, I suggest, lies in the issue of power, and specifically the question of who holds the power when it comes to the internet. There has been much talk in recent years of the death of the Westphalian State, in which rising cosmopolitanism enabled by the extraordinary geography-defying power of the internet can fuel both positive and dangerous political movements in ways never seen before. The new politics of President Trump's administration in 2016-20 saw the leader of the most powerful state on the planet increasingly turn to Twitter rather than to established parliamentary mechanisms, or indeed to the recommendations of his own intelligence services. Despite the chorus of anxiety about "Twitter diplomacy", perhaps Trump understood better than many the populist power enabled by social media, and the way in which it could side-step the established and orthodox channels of democracy.

Such a process has perhaps reached a new level of concern with the storming of the Capitol building in January 2021. But where does all of this leave the power of the state, and of its organs of decision-making such as the Congress and attendant processes? One could argue that, even with the unedifying recent events in Washington DC, the Senate was only interrupted in its duties for a few hours and resumed later the same day.

There is also the big question of who actually owns the internet. No single state owns it, clearly, but does that mean that the major ISPs who dominate the communications channels are in pole position when it comes to power and influence? Within the debates about security and the decline of Westphalianism, there is a suggestion that the state has gradually declining 
power over its ability to hold a monopoly on the use of force to deliver its writ: a process described by Hedley Bull as a New Medievalism (Bull, 1977). But how far is this actually true, when the state still holds hefty levers of power such as licensing, taxation, and legislation? And what of China's suggestion that the internet is an organ of Western-dominated globalisation and liberal democracy, and perhaps the best way for the authoritarian state to reassert its power over the populace is to split the network up into regional "splinternets" that it can better control? If such a development is coming to pass, what effect will it have on regional and global politics and social movements?

Indeed, in authoritarian states such as China and Russia, the domestic questions of the state having influence over what can and cannot be promulgated over the internet are less complicated than they are in the West, notwithstanding the considerable technical challenges. But in Western liberal democracies, how does a concern over the rise of anti-democratic VTSMs and a desire to forge counter-extremism policy, conflict with the principles of freedom of expression and non-interference by a small state? There might also be an economic dimension, which, I would argue, is causing Western states to dance a complicated line around the desire to regulate "big Tech" behemoths, while not discouraging the growth and development of the hightech sector in their own economies. For a country such as the UK, for example, this is a particularly complex question when considering the postBrexit period and an opportunity - perhaps - to put some more clear blue water between itself and the EU when it comes to regulation and "red tape" for ISPs and related industries.

\section{The extremist propaganda context}

One thing that research is showing in recent years is that the internet offers tremendous new powers of amplification for traditional notions of the "power of the mob", when it comes to promulgating inflammatory communications. In an excellent study of the factors that cause concern with internet-based communications, RAND Corporation's "firehose of falsehood" model provides a framework for understanding how the massively increased speed, volume, and frequency with which communications can be spread over the internet, run ahead of traditional methods of communication by a significant distance (Paul and Matthews, 2016). Perhaps more importantly, they also play problematically into human cognitive pitfalls, such as a tendency to accord more importance to views apparently shared by a large number of people, and to the most recent and frequently heard piece of information (problems characterised by the infamous "confirmation bias" and "frequency heuristic"). For those driving violent extremist movements, an advanced understanding of how such factors can be used to advantage when spreading 
extremist propaganda can be a very useful and dangerous tool in spreading extreme narratives.

It seems clear that, in the international terrorism environment, the groups with global aspirations such as Al Qaeda who emerged in the late 1990s, saw merit in a more decentralised and ideologically-driven model than had previously been the case with more established terrorist groups. Although much debated, Marc Sageman's "leaderless jihad" thesis, published in 2008, characterised how such groups had very effectively recognised and capitalised upon the notion of a dispersed and decentralised method of radical and extreme communication to drive diverse attacks around the globe (Sageman, 2008). The Islamic State group that spun out of Al Qaeda at around the same time has clearly adopted a similar methodology, in which individuals with little or no direct contact with the leadership of the group can mount an attack and declare they were a "soldier of ISIS". The group, in turn, can claim responsibility for any number of attacks which may or may not have had anything to do with them.

With the rapid expansion of internet-based communications methodologies over the same period of the early twenty-first century, the nexus between the communications-at-scale opportunities offered by social media, and decentralised extreme movements and ideologies, seems obvious. A growing capability in the exploitation of such technology for planning and communicating is increasingly being seen in the criminal, as well as the extremism environment, especially in such arenas as sexual exploitation (NCA, 2020:8). In the Extreme Right-Wing (XRW) environment, meanwhile, there is evidence that grassroots activists traditionally rather limited in their scope, such as Tommy Robinson in the UK, are becoming increasingly adept at forging links with like-minded extremists across geographical boundaries, such as the European PEGIDA movement and AltRight groups in the US, using internet-based methods of communication (Robinson, 2015). Indeed, as such figures rise in social media presence, there is evidence that other disinformation agents in the extremist biosphere will piggy-back on their channels to generate more traffic, in a process known as “@-ing” (Richards, 2021: 101).

\section{A counter perspective}

At the time of writing, the authorities in the US are clearing up the physical and reputational mess of the storming of Capitol Hill, spearheaded evidently by a number of Alt-Right and conspiracy-theorising groups such as QAnon. This incident led to the deaths of five people. The symbolism of a President steadfastly refusing to condemn such actions in social media and the resultant question-marks that hang heavy over the democratic process, are difficult to ignore or downplay. Indeed, Kelshall (2019: 1) argues that the effect of 
VTSMs so unleashed by such messages from the top is profound: an effect of "changing the weather" in social interactions that materially complicate and exacerbate internal conflict in society. While the problem here is more immediately a security one, rather than about structural political shifts per se, it seems highly likely there will be a significant longer term effect when viewed through this lens.

At the same time, these tragic and troubling events have to be placed in the appropriate perspective. In terms of existential threats to democracy, we have to ask the questions: how much influence does disinformation and malicious content on the internet actually have on wider opinions in the electorate? What effect do the much-discussed echo chambers and filter bubbles have on the overall impact of malicious information? If, in the face of these threats, governments not only continue to be able to proceed through their constitutional programme, but also introduce binding legislation targeting nefarious or irresponsible actors in the online communications space, could we not argue that states still very much hold the reins of power?

We should also consider that these phenomena are not static affairs but are continually evolving in ways that may be difficult to predict. As the Trump administration reaches its violent nadir, for example, might it be the case that extremist movements fuelled by the propagation of nefarious communications have a limited shelf-life, in which a lack of overall progress towards changing the establishment eventually leads to disillusionment and decay?

There are two political dimensions to consider here. The first is whether and how XRW or other extreme populist parties on the left or the right can achieve real political change within democracies. This is where research into the fortunes of extreme political parties is very enlightening, and it shows that, for all the electoral gains of extreme parties in recent years in Europe, for example, very few have hitherto managed to reach much more than around 15 percent of the vote in any specific country and thus to be anything other than minor coalition partners. In some countries, such as the UK for example, right-populist parties have never achieved a single parliamentary seat in elections, with the exception of the right-wing UK Independence Party (UKIP; which many, including themselves, would vehemently deny should be classified as an XRW party and is perhaps better described as rightpopulist).

As Voogd and Dessonneville (2018) argue, supporters of populist parties are traditionally considered to be "volatile" in terms of their support over time. This may be especially so where parties built on an exclusive and oppositionist ideology find it difficult to adapt to the everyday and frankly 
mundane business of governance when power is achieved. Analysis suggests this volatility is not necessarily as powerful as we might think (Voogd and Dassonneville, 2018: 15). This will be a very interesting factor to watch in the contemporary environment, especially, perhaps, in the US following Trump's failure to achieve a second term and the longer-term effect this may have on his core support base.

The second dimension here is that many extreme movements fuelled by the internet space are just that: they are movements and not parties. This means that, while they can make waves in terms of direct action on the streets, including agitation or even murderous attacks on occasion, they are not necessarily able to effect much deep political change unless they are directly supported by a political actor inside the system. The Proud Boys, QAnon, and many others, for example, might be able to make headlines, but they could be argued to have a very limited direct effect on the machinery of government, when all is said and done. In some ways, their very rejection of democracy and of the supposed elites who run it, may be their achilles heel in effecting real change.

\section{Empirical research into the effect of extremist material on the internet}

It is clearly the case in such a high-profile and controversial situation that empirical research on the true effect of malicious information on the political process will be critically important. Various strands of research are indeed starting to emerge which will help shed light on the situation.

Considering the events of the "Arab Spring" which opened our discussion, the normative thesis has generally been that social media was pivotal in effecting political change. In a paper for the Project on Information Technology and Political Islam, for example, Howard et al (2011: 2) observed that "social media played a central role in shaping political debates in the Arab Spring". Later analyses, however, have started to be more nuanced. Markham (2014: 91), for example, reminds us that social media is social and that much of its political content is mixed in with "political vacuity" (although this should not be interpreted to mean that a platform such as Facebook is inherently "apolitical"). Smidi and Shahin (2017: 199-200) remind us of a number of arguments against exaggerating the importance of social media in the unrest in Arab world, including the suggestion that it might have been more a supplementary logistical mechanism for organising activities rather than a strategic driver of political change. The deeper structural factors of income disparity and economic stress may have been much more important, perhaps bringing us back to the idea that the internet itself is at least partially apolitical: a means rather than an end. 
Other strands of research have looked at the potential role of social media or the internet more generally in facilitating recruitment into extremist and terrorist movements. A number of studies, many of them, latterly, looking at groups of "jihadists" motivated to travel to Iraq and Syria to fight with ISIS and similar groups, have suggested that, while social media and the internet are clearly an important factor, the perennial importance of direct physical contact with inspirational figures is still predominant (Richards, 2020: 69). This may explain why specific geographical clusters have tended to deliver disproportionate numbers of "foreign fighters" to the conflict, rather than a more evenly-spread picture.

Other studies have looked at the potential effect of organised disinformation around the times of votes and referenda, to attempt to determine the political effect of such activity. A flurry of votes in the Western world since 2014 have been the subject of much analysis, notably the Scottish independence referendum of 2014; the "Brexit" referendum in the UK of 2016, and the presidential elections in the US in the same year, to name but a few (Richards, 2021). Some of the studies of disinformation around these votes have concluded that the "bad" information on social media (a proportion of it promulgated by organised bot and troll activity emanating from Russia) was a very small proportion of the total information landscape to which voters had access. The study by Llewellyn et al (2019: 1153) found that on the Brexit referendum polling day in the UK, the amount of activity by identified malicious troll accounts within a sample set of over a million tweets represented just 0.037 percent of overall activity. They also found that much of the malicious social media activity actually occurred after the event, meaning that it could not have had much effect on the vote itself (although could have had a longer-term strategic purpose in disrupting political views).

Similarly, in their analysis of "fake news" on Twitter during the 2016 US presidential campaign, Grinberg et al (2019: 377) found that "the vast majority of fake news shares and exposures..." analysed in their sample sets "...were attributable to tiny fractions of the population". Analysis of fake news during the same elections on the Facebook platform by Guess, Nagler, and Tucker (2019) provides a further level of detail on the structural factors within different communities coming into contact with disinformation. These findings suggested that slightly more Republican voters and slightly more users in the older age bracket (65 years and above in this particular study) were more likely to recirculate fake news stories they encountered than other groups, although the difference compared to other groups was very small. The overall amount of sharing of fake news stories "was a rare activity" compared to general traffic flows during the election (Guess et al, 2019: 1). 
While these are not the only analyses in circulation and more empirical work is needed over time, they do point to a suggestion that the political effect of extreme or otherwise malicious information on the internet may be very small when contextualised within the overall information landscape.

What of "echo chambers" and "filter bubbles" and the effect they have on wider political opinion? A normative hypothesis may be that, if people tend to restrict their interactions with largely like-minded people and sources, then the wider effect of disinformation will be relatively contained within closed groups. Again, research is delivering varied and nuanced judgements on this thesis. Research by Flaxman, Goel and Rao (2016) on a sample set of USbased web users found that, on the one hand, there was evidence of "higher ideological segregation" in the items selected from social media and webbrowsing for certain groups of individuals than was the case with direct visits to established news sites, suggesting an echo-chamber effect. At the same time, the non-mainstream sites visited actually displayed a reasonable diversity of views across their content, suggesting that such users were no less likely to be exposed on those channels to diverse perspectives than were others (Flaxman et al, 2016: 318). Again, this suggests a smaller effect of such information on political opinion than is sometimes supposed, especially when it is placed within the context of the broad information landscape to which we are all irretrievably exposed in the contemporary environment.

\section{Conclusions}

When considering the politics of the internet in the context of the nature and effect of extremist propaganda, the first question is how far the internet, and internet-based communications, are in themselves political agents or spaces. At one level, the internet is merely a vessel within which information is held. This sense is reinforced by the recognition that the internet is not owned or operated by any particular state or organisation. With that said, the operators of the communications services that sit on the internet are very specific organisations, and it is fair to say that the larger Internet Service Providers (ISPs) have definitely come within the purview of government policy and legislation in recent years for their supposed role in encouraging or not suppressing harmful content on their networks.

In some jurisdictions, the political optics in this area have been authoritarian and punitive. In the case of Germany, for example, a new law passed in 2018 called the Network Enforcement Act (NetzDG) levies a requirement on social media companies to remove "hate speech" on their networks within 24 hours, or be fined 20 million euros (DCMS, 2019: 13). 
In other countries, such as the UK for example, the emerging government narrative is somewhat more nuanced. Here, the government appears to be trying to strike a complex balance between tapping into the political discomfort about the perceived negligence of major ISPs in the area of controlling extremist content, and not wanting to seem like an antidemocratic and authoritarian state that is overstepping the boundaries of free speech and liberalism. There is also the economic consideration of not wanting to drive tech business away from the national economy through overly punitive and bureaucratic measures (Richards, 2021). In this sense, the political aspect is not so much about the effect of the harmful content itself, but about whether and how the government tackles the perceived problems and how it will be judged by the electorate accordingly.

There is also the evidential question of how much effect extremist and other harmful content on the internet actually has on individuals' opinions and actions. Even with the most recent situation in Washington DC, in which the President appeared to verbally facilitate violent action in physical space, we have to contextualise the situation and critically consider how far it was indicative of wider processes. The trigger for the violence, after all, was that the President had lost the election and been rejected at the ballot box (albeit with a very sizeable support base of his own). It is also the case that, while the machinery of Congress was temporarily and unprecedentedly interrupted by the situation, it did not remain that way for very long. The grinding wheels of government soon started up again and returned to the task on which they had been previously engaged, namely to formally approve the result of the election.

This leads to two proposed judgements. Firstly, there is evidence to suggest that extreme content on the internet does not necessarily have as much lasting effect on the political process as we might suppose, in a number of ways. It may be that the extremism that flows from such a phenomenon is relatively limited in scope in terms of the constituencies to which it speaks; that much of it is more about facilitating operational activity rather than effecting deeper strategic change in opinion; and that the eventual result on the political process in terms of delivering lasting damage to the mainstream purveyors of democracy may be fundamentally ineffectual. In a sense, the fact that many of the extremists who promulgate and consume extremist material are more readily classified as movements rather than parties means that, while they may sometimes generate headlines, they are still some way off being able to fundamentally change the system. This is not least because they place themselves outside of the system altogether.

The second key judgement is that, for all the talk of the collapse of the Westphalian state, and indeed of the end of liberal democracy, I would 
propose that the state is still very much in the driving seat and still has access to a number of levers of power that are not available to other, non-state actors on the internet. This part of the argument is all about power. I would propose that the state still has the power to regulate and shape the internet, while the other actors in the triumvirate relationship - the ISPs and the population's cosmopolitan movements - can still do little other than make waves in cyberspace or occasionally on the streets; or indeed to take their business elsewhere. Recent events have shown that, while the grinding wheels of government and bureaucracy may sometimes be agitated by such actions, they are still very much in place and are unlikely to be derailed in the foreseeable future. 


\section{References}

Bull, H. (1977). The Anarchical Society. A Study of Order in World Politics. New York: Columbia University Press.

DCMS. (2019). Disinformation and "fake news": Final Report. Eighth Report of Session 2017-19. London, House of Commons, HC 1791. Retrieved 15 August 2020, from https://publications.parliament.uk/pa/cm201719/cmselect/cmcumeds /1791/179102.htm

Fake news, disinformation and the democratic state: a case study of the UK government's narrative. (2021). Icono 14, 19(1), 95-122.

Flaxman, S., Goel, S. and Rao, J.S. (2016). Filter bubbles, echo chambers, and online news consumption. Public Opinion Quarterly, 80, 298320.

Grinberg, N., Joseph, K., Friedland, L., Swire-Thompson, B. and Lazer, D. (2019). Fake news on Twitter during the 2016 U.S. presidential election. Science, 363, 374-378.

Guess, A., Nagler, J. and Tucker, J. (2019). Less than you think: Prevalence and predictors of fake news dissemination on Facebook. Science Advances, 5(1), 1-8.

Howard, P.N., Duffy, A., Freelon, D., Hussain, M., Mari, W., and Mazaid, M. (2011). Opening Closed Regimes: What was the Role of Social Media During the Arab Spring? Project on Information Technology and Political Islam (PITPI), Working Paper 2011.1.

Kelshall, C. (2019). Violent Transnational Social Movements and their Impact on Contemporary Social Conflict. Journal of Intelligence, Conflict and Warfare, 1(3), 1-16.

Llewellyn, C., Cram, L., Hill, R.L. and Favero, A. (2019). For Whom the Bell Trolls: Shifting Troll Behaviour in the Twitter Brexit Debate. Journal of Common Market Studies, 57(5), 1148-1164.

Markham, T. (2014). Social media, protest cultures and political subjectivities of the Arab Spring. Media, Culture and Society, 36(1), 89-104.

NCA. (2020). National Strategic Assessment of Serious and Organised Crime 2020. Retrieved 3 January 2021 from https://www.nationalcrimeagency.gov.uk/who-weare/publications/437-national-strategic-assessment-of-serious-andorganised-crime-2020/file

Paul, C. and Matthews, M. (2016). The Russian "Firehose of Falsehood" Propaganda Model. RAND Corporation, Perspective, PE-198-OSD [2016]

Richards, J. (2020). Down but not out? Revisiting the terror threat from foreign fighters. International Journal of Intelligence, Security and 
Public Affairs, 22 (2), 61-81.

Robinson, T. (2015). Enemy of the State. Batley: The Press News.

Sageman, M. (2008). Leaderless Jihad: Terror Networks in the TwentyFirst Century. Philadelphia: University of Philadelphia Press.

Smidi, A., and Shahin, S. (2017). Social Media and Social Mobilisation in the Middle East: A Survey of Research on the Arab Spring. India Quarterly, 73(2), 196-209.

Voogd, R., and Dassonneville, R. (2018). Are the Supporters of Populist Parties Loyal Voters? Dissatisfaction and Stable Voting for Populist Parties. Government and Opposition, 1-22

\section{$(\mathbb{1 0 \Theta}$}

NonCommercial-NoDerivatives 4.0 International License.

(C) Julian Richards, 2021

APA Citation:

Richards, Julian. (2021). Extremist propaganda and the "politics of the internet." The Journal of Intelligence, Conflict, and Warfare, 3(3), 22-33.

Published by the Journal of Intelligence, Conflict and Warfare and Simon Fraser University

Available from: https://jicw.org/ 